\title{
EL PROBLEMA DE LA LENGUA ESPAÑOLA EN AMÉRICA
}

El gran problema - acaso el único problema grave- de la lengua española en su totalidad - a uno y otro lado del océanoes el de la posibilidad de su fragmentación en un futuro más o menos remoto. Tal fragmentación podría estar aún muy lejana, a muchos siglos de distancia, pero su proceso, lento y callado, podría haber comenzado hace ya tiempo.

No fue Rufino José Cuervo, sino Andrés Bello, quien por primera vez expresó el temor de que la lengua española pudiera llegar a fragmentarse en diversos idiomas nacionales. Tratar de impedir tan terrible calamidad fue uno de los motivos que le impulsaron a escribir su famosa Gramática de la lengua castellana, en cuyo prólogo - no debemos olvidarlo nuncaadvertía: "Juzgo importante la conservación de la lengua de nuestros padres en su posible pureza, como un medio providencial de comunicación y un vínculo de fraternidad entre las varias naciones de origen español derramadas sobre los dos continentes" 1 . Pero tal conservación parecía difícil por causa de los vicios anfibológicos, los neologismos innecesarios y otros males que ponían en peligro la salud de la lengua española. Ante los cuales, el gran venezolano señalaba:

Pero el mayor mal de todos, y el que, si no se ataja, va a privarnos de las inapreciables ventajas de un lenguaje común, es la avenida de los neologismos de construcción, que inunda y enturbia mucha parte de lo que se escribe en América, y alterando la estructura del idioma, tiende a convertirlo en una multitud de dialectos irregulares, licenciosos, bárbaros; embriones de idio-

${ }^{1}$ Cito por la edición de sus Obras completas, con prólogo de Amado Alonso, hecha por el Ministerio de Eduación de Venezuela, Caracas, 1951. La cita corresponde a la p. 11. 
mas futuros, que durante una larga elaboración reproducirían en América lo que fue la Europa en el tenebroso período de la corrupción del latín. Chile, el Perú, Buenos Aires, Méjico, hablarían cada uno su lengua, o por mejor decir, varias lenguas, como sucede en España, Italia y Francia ${ }^{2}$.

Aunque en un primer momento Rufino José Cuervo no parecería abrigar temor alguno por el porvenir de la lengua española en América, a partir de 1899 su pensamiento, como bien se sabe, cambió radicalmente. Recordemos el célebre pasaje de la carta que escribió a don Francisco Soto y Calvo en aquel año:

...las divergencias debidas al clima, al género de vida, a las vecindades y aun qué sé yo si a las razas autóctonas, se arraigan más y más y se desarrollan; ya en todas partes se nota que varían los términos comunes y favoritos, que ciertos sufijos o formaciones privan más acá que allá, que la tradición literaria y lingüística va descaeciendo y no resiste a las influencias exóticas. Hoy sin dificultad y con deleite leemos las obras de los escritores americanos sobre historia, literatura, filosofía; pero en llegando a lo familiar o local, necesitamos glosarios. Estamos pues en vísperas (que en la vida de los pueblos pueden ser bien largas) de quedar separados, como lo quedaron las hijas del Imperio Romano: hora solemne y de honda melancolía en que se deshace una de las mayores glorias que ha visto el mundo, y que nos obliga a sentir con el poeta: ¿Quién no sigue con amor al sol que se oculta?3

Sobre la conocida polémica entre don Juan Valera y el propio Cuervo ${ }^{4}$ a que dieron lugar estas apreciaciones, han escrito ampliamente Ramón Menéndez Pidal y Guillermo Guitarte. Para el primero, el radical cambio de opinión que se produce en Cuervo respecto del futuro de la lengua española es fruto de una actitud pesimista debida a "los achaques de la senectud", que contrasta violentamente con el inicial optimismo de

2 Ibid., p. 12. Lo cual, como antes he indicado, le impulsó a escribir su Gramática: "Sea que yo exagere o no el peligro, él ha sido el principal motivo que me ha inducido a componer esta obra".

${ }^{3}$ Cf. El castellano en América. Cito por la edición de las Obras hecha por el Instituto Caro y Cuervo, Bogotá, 1954, pp. 520-521.

${ }^{4}$ Reseñada por Paciencia OnTaÑón en su tesis sobre La posible fragmentación del español en América. Historia de un problema, UNAM, México, 1967, pp. 43-66. 
Cuervo cuando estaba "en plena lozanía de su espíritu, en 1885"5; para el segundo, dicho cambio "no representa una caída desde la madurez a la debilidad senil, sino el pasaje del pensamiento de un joven que vivía en una «casi ignorada cumbre de los Andes» al de la plenitud del hombre de ciencia establecido en París"6.

La enorme trascendencia de la posibilidad de que se produjera algún día tal fragmentación idiomática determinó que en 1963 se celebrara en Madrid un gran congreso de filología en que se prestó atención, de manera muy particular, al futuro inmediato de la lengua española ${ }^{7}$. Las conclusiones a que en él se llegó fueron esperanzadoramente optimistas: nada hacía temer una próxima descomposición de la lengua española. El vaticinio de Cuervo no parecía estar bien justificado, ya que las condiciones histórico-culturales que llevaron a la fragmentación del latín y a su transformación en las diversas lenguas románicas durante la Edad Media eran radicalmente distintas de las que prevalecen en el mundo actual.

No obstante todo ello, un filólogo tan autorizado como Dámaso Alonso siguió pensando que la unidad de la lengua española estaba en grave peligro. Años antes de que ese congreso se celebrara, había expresado ya Dámaso Alonso sus temores:

Por todas partes dentro del organismo idiomático hispánico se están produciendo resquebrajaduras: éstas afectan tanto a lo fonético como a lo sintáctico, a lo morfológico o al léxico... El edificio de nuestra comunidad idiomática está cuarteado ${ }^{8}$.

Por lo cual hacía suya la proclama hecha por Menéndez Pidal años antes: "Tenemos que poner todo nuestro esfuerzo para

${ }^{5}$ Cf. su estudio sobre "La unidad del idioma", en el libro Castilla, la tradición, el idioma, Buenos Aires, 1945, p. 180.

${ }^{6}$ Cf. su artículo sobre "El origen del pensamiento de Rufino José Cuervo sobre la suerte del español de América", en Logos semantikos: Studia linguistica in Honorem Eugenio Coseriu, Gredos, Madrid-Berlin-New York, 1981, t. 1, p. 445 .

${ }^{7}$ Con el título de Presente y futuro de la lengua española se publicaron dos volúmenes de las "Actas de la Asamblea de Filología del I Congreso de Instituciones Hispánicas”, Ediciones Cultura Hispánica, Madrid, 1964.

${ }^{8}$ Cf. su ensayo sobre "Unidad y defensa del idioma", Memoria del II Congreso de Academias de la Lengua Española, Comisión Permanente de la Asociación de Academias, Madrid, 1956, pp. 33-48. (La cita corresponde a la p. 43.) 
evitar la fragmentación de nuestra lengua"9; o, con sus propias palabras, para "impedir que nuestra lengua se nos haga pedazos" (Unidad, p. 36).

Cierto es que, en años posteriores, rectificó Dámaso Alonso su acaso excesivamente pesimista actitud, y reconoció que la integridad de la lengua española no estaba, por el momento, seriamente amenazada. Pero no podemos dejar de pensar que el peligro, la posibilidad de fragmentación lingüística existe siempre, aunque se trate de un lento proceso que haya de requerir de muchos siglos para su cumplimiento. Y así lo reconoció el propio Alonso en ese congreso a que me he referido líneas antes: "Como ya he dicho en otra ocasión, no veo peligros graves para el castellano en el período que llamo futuro histórico, aunque en lo que llamo posthistoria haya de llegar a su desaparición como tal lengua, probablemente por evolución diversificadora"10.

Inevitable parece, racionalmente, que suceda tal cosa. Toda lengua hablada en territorios muy extensos, como sucede en el caso del español, irá diferenciándose paulatinamente con el correr del tiempo en sus diversos dominios, hasta llegar a una posible fragmentación. El peligro es aún mayor en el caso de que tal lengua no esté gobernada, dirigida, por un solo centro que sirva de modelo a las hablas de todos los demás territorios y dé cohesión y uniformidad a la inevitable evolución de todo sistema lingüístico. En el caso de la lengua castellana no existe ya el gobierno o la rección del centro metropolitano español que daba la pauta a las hablas hispanoamericanas durante los tres siglos de dominio español en América. Hoy nuestra lengua se habla en 19 países soberanos, en cada uno de los cuales existe un foco lingüístico rector — cuando no dos o más-que origina o impulsa cambios no compartidos siempre por las demás hablas hispánicas. Si tales cambios o innovaciones se multiplican, la diferenciación dialectal irá ahondándose más y más, incubando así al fantasma de la fragmentación lingüística.

Aunque cierto es, por otro lado, que el estrecho contacto que pueden mantener entre sí, en el tecnificado mundo moderno, las diversas hablas hispánicas, así como la deseable vo-

${ }^{9}$ Cf. D. Alonso, "Nuestro idioma nos hace hombres", Universidad de Antioquia, 36 (1960), 747-750. (El epígrafe citado, en la p. 747.)

10 Cf. su ponencia "Para evitar la diversificación de nuestra lengua", en Presente y futuro (cit. supra, n. 7), pp. 259-268. De las luminosas ideas de Dámaso Alonso en torno a este tema me he ocupado en el artículo sobre “'Dámaso Alonso y el futuro del español’', ALM, 29 (1991), 279-291. 
luntad de conservar la homogeneidad fundamental de la lengua por parte de todos los países hispanohablantes, son buena garantía de que el futuro inmediato - y aun a largo plazo- de nuestro idioma parece estar asegurado. Pero es preciso que subsista y se fortalezca esa voluntad de unión idiomática, de comunidad lingüística hispánica o hispanoamericana, que garantizaría el venturoso porvenir de la lengua española.

Posiblemente por ello, creo que la labor del gramático, del lingüista, del filólogo, no puede limitarse a ser —al menos en el caso de la lengua española- pura y estrictamente descriptiva, según aconsejan, o aun prescriben, algunos autorizados lingüistas de nuestro tiempo. Como, muy expresa y tajantemente, ha hecho André Martinet. Para quien la lingüística, si quiere ser verdaderamente científica, habrá de mantenerse dentro de los límites del más riguroso descriptivismo, sin tratar de ser nunca prescriptiva ni normativa ${ }^{11}$. Cosa con que no puedo estar de acuerdo, puesto que no alcanzo a entender por qué un gramático, tras de estudiar algún hecho lingüístico, haya de tener "científicamente" prohibido advertir o señalar que tal hecho es anómalo y, en consecuencia, impropio o aun incorrecto. No veo por qué seré anticientífico si advierto, por ejemplo, que en el habla mexicana la pluralidad del complemento indirecto ( $a$ ellos), no pudiendo indicarse morfológicamente en la forma pronominal invariable $s e$, se traspasa al nombre complementario directo $l o-$ en la secuencia se lo-, diciendo "[El libro] ya se los di [a ellos]", y añado que tal uso es impropio, incorrecto, puesto que el pronombre lo, representante de un libro, es singular y no debe recibir el morfema de pluralidad correspondiente a $s e^{12}$. Una de las modernas ramas de la lingüística

11 'La linguistique est l'étude scientifique du langage humain. Une étude est dite scientifique lors qu'elle se fonde sur l'observation des faits et s'abstient de proposer un choix parmi ces faits au nom de certains principes esthétiques ou moraux. «Scientifique» s'óposse donc à «prescriptif». Dans le cas de la linguistique, il est particulièrement important d'insister sur le caractère scientifique et non prescriptif de l'étude"' (A. Martinet, Eléments de linguistique générale, Armand Colin, Paris, 1960, cap. 1).

${ }^{12}$ La nada desdeñable tradición lingüística española -o hispanoamericana- ha sido, hasta muy entrado este siglo xx, no sólo científicamente descriptiva, sino a la vez atinadamente prescriptiva, normativa, según he tratado de mostrar en la ponencia sobre la "Actitud de Nebrija ante la lengua castellana”, presentada en el Congreso sobre Elio Antonio de Nebrija organizado en octubre de 1992 por las Universidades Salamanca y Sevilla, cuyas actas aparecerán muy en breve. 
contemporánea es la que se ha dado en llamar lingüistica apli$c a d a$, uno de cuyos dominios principales es el de la enseñanza de lenguas: ahora bien, ¿qué se debe enseñar? Peculiaridad es de cualquier idioma la variedad y la complejidad de sus diversas normas o usos. La norma popular o rural de muchos países hispanohablantes admite, por ejemplo, la concordancia del impersonal haber con lo que gramaticalmente es su complemento directo, no su sujeto, de manera que dentro de ella cabe decir "Habemos muchas personas que pensamos así"; pero la norma culta mantiene el uso impersonal del verbo haber y dictamina que la construcción correcta es "Hay muchas personas que piensan asî"13. Al aplicar estos conocimientos a la enseñanza de la lengua española, ¿qué habremos de enseñar como preferible, como correcto, como normal? Evidentemente que no "Habiamos muchos", sino "Hay muchos", así como no "Eso ya se los dije a ellos", sino "Eso ya se lo dije a ellos". Toda lengua abarca varias normas, varios tipos de realizaciones, cada una de las cuales gozará de distinto prestigio y aprecio, aunque no siempre sea por causas estrictamente lingüísticas - como en el caso de se los-, sino por razones históricas, sociales y culturales. Pero no podemos olvidar que toda lengua no es sólo un sistema de signos y de funciones —un sistema gramatical-, sino también un sistema, un hecho histórico, social y cultural. Afortunadamente.

La actividad normativa y aun correctiva que juzgo necesaria, sobre científica, obliga a analizar y a delimitar la norma -o las normas- de prestigio o paradigmáticas. Esto es, las realizaciones que deben tenerse como modelo de la buena expresión, oral o escrita. La determinación o elección de esa norma superior o ejemplar puede resultar ser tarea difícil y delicada. Y más en el caso de la lengua española, hablada como propia en casi una veintena de países soberanos. Cada uno de los cuales posee su propia norma de prestigio, cuando no - como antes apuntaba- dos o más: que no es la misma exactamente el habla de Buenos Aires que la de Córdoba o Mendoza, por ejemplo ${ }^{14}$.

$13 \mathrm{O}$, incluyéndose en el sujeto el propio hablante, "Somos muchos los que pensamos asî́".

${ }_{14} \mathrm{Ni}$, dentro de México, es exactamente igual la norma culta yucateca, por ejemplo, que la mexicana capitalina. En aquélla, las llamadas oclusivas sonoras / p t k/ intervocálicas pueden ser efectivamente oclusivas, en tanto que en la norma mexicana - como en la de la mayor parte de los territorios hispanohablantes - tales fonemas son fricativos; en aquélla, el cabello 
Claro está que las normas superiores del español usado en cada uno de esos países coinciden plenamente entre sí en la inmensa mayoría de las ocasiones. El sistema fonológico es prácticamente el mismo en todas partes, con aisladas discrepancias en algunos de ellos ${ }^{15}$, amén de las diferencias puramente fonéticas, que en algunas ocasiones llegan ya a dificultar la comunicación entre hispanohablantes de países distintos. Más abundantes son, obviamente, las diferencias de carácter léxico, que colorean y diversifican a cada una de las hablas hispánicas; pero el fondo patrimonial léxico es todavía común a todos los países hispanohablantes. Y la homogeneidad del sector morfosintáctico, que es el nuclear y básico del sistema lingüístico, es todavía mucho mayor o más firme. Volveremos sobre esto más adelante.

A esa coincidencia fundamental, esencial y básica, de las diversas normas nacionales entre sí, se añade otro factor que considero de máxima importancia. Y es la existencia de una norma hispánica ideal o, si se prefiere, de un ideal de lengua hispánica, al menos entre las personas que están conscientes del carácter histórico y cultural de la lengua, o sea que poseen un concepto claro de lo que es un idioma como hecho histórico, cultural y social —en una palabra, humano—, según apuntaba líneas arriba. Esa norma hispánica ideal sería el paradigma superior al que todos los hispanohablantes conscientes tratamos de aproximarnos cuando pretendemos hablar o escribir bien. Aspiración lingüística que, como he apuntado en otro lugar ${ }^{16}$,

$\overline{\text { no puede }}$ er chino, como en la capital del país, sino sola y adecuadamente rizado. Norma propia del habla del estado sureño de Chiapas es el voseo, desconocido en el resto de México. No es necesario acumular aquí ejemplos de la variedad de normas válidas o de prestigio dentro de un mismo país.

15 Pienso en casos como el ensordecimiento de las palatales rehiladas, común ya en ambas orillas del Río de la Plata, en formas como [mášo] o [táša] —por mayo o talla—, más identificables acústicamente para oídos no rioplatenses con macho o tacha que con mayo o talla. Y pienso también en la redistribución de sibilantes que, con un poquito de mala voluntad, podría establecerse dentro del sistema fonológico mexicano, debido a la existencia en él de un fonema prepalatal fricativo sordo /šs en voces de procedencia amerindia, como mixiote [mišjóte], asunto a que he atendido en otro lugar. (Cf. "La influencia del sustrato en la fonética del español de México", RFE, 50, 1967, 145-148.)

16 Cf. "El español de América y la norma lingüística hispánica”, en $E l$ español de América: Actas del III Congreso Internacional, eds. C. Hernández Alonso et al., Junta de Castilla y León, Valladolid, 1991, t. 3, pp. 1179-1184. (Recogido también en mi libro Nuevos estudios de lingüística hispánica, UNAM, México, 1993, pp. 127-136.) 
no es sino uno de tantos medios a través de los cuales se manifiesta el afán de superación que caracteriza a la especie humana y que ha sido la base fundamental de su desarrollo y progreso a través de los siglos.

Acabo de señalar que todas y cada una de las normas de prestigio coinciden básicamente entre sí en la inmensa mayoría de los casos. Pues bien, esa infinitud de formas y de construcciones en que coinciden todas las normas lingüísticas nacionales o regionales que integran la lengua española serían las constituyentes de la norma hispánica general. "Ayer le di tu recado" es un enunciado de validez hispánica, por cuanto que pertenece a todas y cada una de las normas particulares, y por ello se constituye en norma general, en construcción válida por doquier. No lo sería, en cambio, "Antier le he dado tu encargo", por cuanto que antier no es forma válida - por anteayer - en todas las hablas prestigiosas del mundo lingüístico hispánico; ni el pretérito compuesto se emplea en ellas para referirse a hechos cumplidos en un lapso que no abarca al ahora del acto de la palabra; ni, finalmente, el sustantivo encargo funciona en todas ellas con el significado de 'recado'.

Cierto es — repito- que cada una de las hablas regionales o nacionales de la lengua española coincide con todas las demás en la inmensa mayoría de los casos, especialmente en lo que respecta al sector básico y nuclear de la morfología y la sintaxis. Pero no es menos cierto que en todas ellas existen formas o construcciones privativas, que las distinguen de las demás, particularmente en los dominios de la fonética y, sobre todo, del léxico. Y no cabe duda de que todas esas peculiaridades particulares - regionales o nacionales - tienen plena validez dentro del ámbito geográfico en que predomina la norma que las admite como buenas. Los llamados dialectalismos son válidos dentro del dialecto a que pertenecen, aunque puedan ser rechazados por la norma hispánica superior. Y esto debe aplicarse tanto a los dialectos espaciales o geográficos, cuanto a los sociales o culturales. Cosa que muy bien sabía - y proclamaba- ya a comienzos del siglo XVII Gonzalo Correas, cuando hizo el diseño genial de lo que en nuestro tiempo ha dado en llamarse sociolingüística. Decía el gran humanista español:

Ase de advertir que una lengua tiene algunas diferenzias, fuera de dialectos particulares de provinzias, conforme a las edades, cualidades, i estados de sus naturales, de rrústicos, de vulgo, de 
ziudad, de la xente más granada, i de la corte, del istoriador, del anziano i predicador, i aun de la menor edad, de muxeres i varones: i que todas estas abraza la lengua universal debaxo de su propiedad, niervo i frase: $i$ a cada uno le está bien su lenguaxe, i al cortesano no le está mal escoxer lo que pareze mexor a su propósito, como en el traxe: mas no por eso se a de entender que su estilo particular es toda la lengua entera, i xeneral, sino una parte, porque muchas cosas que él desecha, son mui buenas i elegantes para el istoriador, anziano, i predicador, i los otros ${ }^{17}$.

De acuerdo con ello, habrá que admitir que todos los morfemas, vocablos y construcciones dialectales forman parte de la lengua española, del sistema lingüístico hispánico, si bien unos gozarán de un mayor prestigio que otros según sea el alcance de su empleo: local, regional, nacional o panhispánico.

A la norma hispánica general deberán tratar de aproximarse todos los hablantes de español que tengan consciencia del carácter histórico, social y cultural de nuestro idioma, sin tener por ello que repudiar las peculiaridades de su norma nacional o local, pero sin pretender tampoco anteponer —adoptando una estrecha y pobre actitud localista, de campanario- esas peculiaridades particulares a la norma hispánica general.

Porque esa norma hispánica ideal debe ser —como, de hecho, ya es- el elemento nuclear que aglutine todas las variedades dialectales de nuestra lengua, esto es, el factor de cohesión que permita y propicie la conservación de la unidad lingüística fundamental del idioma español. Ésta es la tarea principal que corresponde realizar no sólo a los gramáticos y filólogos, sino también a todos los hablantes de español, en especial a los que poseen ese sentido histórico y cultural de nuestra lengua que he venido aquí invocando ${ }^{18}$. Y que fue el que inspiró no sólo a Andrés Bello — según antes he apuntado-, sino ya a nuestro primer gramático: Nebrija. Cuyo principal objetivo, al escribir su Gramática castellana, fue el de "fijar" la lengua mediante su

17 Arte de la lengua española castellana (1625). Cito por la edición de Emilio Alarcos García, C.S.I.C., Madrid, 1954; cf. p. 194.

18 A todos los hispanohablantes corresponde tal tarea, conforme había ya señalado, en los albores del Renacimiento español, mente tan lúcida como la de Juan de Valdés: “Todos los hombres somos más obligados a ilustrar y enriquecer la lengua que nos es natural y que mamamos en las tetas de nuestras madres, que no la que nos es pegadiza y que aprendemos en libros" (Diálogo de la lengua. Cito por la edición crítica de Cristina Barbolani de García, Casa Editrice D’Anna, Firenze, 1967; el texto citado, en p. 6.) 
codificación gramatical, para evitar con ello su posible "corrupción" o fragmentación. Advertía Nebrija que las lenguas griega y latina - aunque transformadas oralmente en los diversos idiomas y romances- se habían mantenido a través de los siglos como tales lenguas de cultura gracias a que ambas contaban con tratados gramaticales que habían permitido mantener su unidad ${ }^{19}$; la lengua castellana, en cambio, había estado durante toda la Edad Media "suelta i fuera de regla; i a esta causa a recibido en pocos siglos muchas mudanças", a tal grado que la diferencia existente entre el castellano de su tiempo y el de cinco siglos antes era tanta "cuanta puede ser maior entre dos lenguas". Por lo cual Nebrija, como siglos después Andrés Bello, componía su Gramática para evitar que siguiera "corrompiéndose" sin orden ni regla. Propósito que también hizo suyo quien acaso haya sido el más genial, relativamente, de nuestros gramáticos: Gonzalo Correas. Quien también advertía que "con los prezetos [i reglas] puestos en arte o con la natural arte advertida y puesta en método o conzierto se entienden mexor i conservan las lenguas, como suzede oi a la Hebrea, i Caldea, i antigua Aráviga, i a la Griega, i a la Latina" (p. 130). Y cuando la Real Academia Española inicia sus labores en el siglo XviII, establece en el lema de su escudo el propósito nebrisense de fijar la lengua, además de limpiarla de elementos "corruptores" — como también había aconsejado Juan de Valdés. Hay una trayectoria firme y decidida en nuestra tradición lingüística — la más antigua de la Europa moderna-, a la que no veo por qué hayamos de renunciar ni de sacrificar en aras de discutible modernidad.

Para fijar la lengua y evitar así su posible fragmentación, es necesario limpiarla de impurezas y "vicios" corruptores. Esa saludable finalidad, y no el purismo estrecho o el casticismo trasnochado, es lo que ha impulsado a nuestros mejores gramáticos a luchar por la propiedad de la lengua. Actitud normativa, correctiva, ante las impropiedades lingüísticas ha sido la que asumieron en su momento no sólo Nebrija, Valdés o Correas —quienes por sí solos bastarían para justificar plenamente tal actitud-, sino también Cristóbal Villalón, Bartolomé Jiménez

19 Señala que "la lengua griega, latina. . . por aver estado debaxo de arte, aunque sobre ellas an pasado muchos siglos, todavía quedan en una uniformidad": prólogo de su Gramática de la lengua castellana, Salamanca, 1492. (Cito por la edición de P. Galindo Romero y L. Ortiz Muñoz, 2 ts., Ediciones de la Junta del Centenario, Madrid, 1946. Cf. el texto citado en t. 1, p. 9.) 
Patón, Juan Villar, Vicente Salvá20, hasta llegar a los dos grandes lingüistas hispanoamericanos del siglo pasado: Andrés Bello y Rufino José Cuervo. Del venezolano ya he transcrito, al comienzo de estas páginas, algunas luminosas opiniones. Del colombiano no me resisto a transcribir algunas otras no menos luminosas y certeras, como lo son las que figuran al comienzo mismo del "Prólogo" de sus Apuntaciones críticas sobre el lenguaje bogotano: "Es el bien hablar una de las más claras señales de la gente culta y bien nacida y condición indispensable de cuantos aspiren a utilizar en pro de sus semejantes, ora sea hablando, ora escribiendo, los talentos con que la naturaleza los ha favorecido". Y como autoridad máxima de ese "bien hablar" propone - como había hecho muchos siglos antes Quintiliano- el uso de los buenos y el conocimiento de la gramática:

Siendo el uso y la ciencia del lenguaje las dos bases en que fundamos nuestras decisiones [haré] algunas breves consideraciones sobre ellos: Necesario es distinguir entre el uso, que hace ley, y el abuso, que debe extirparse. Son notas del primero el ser respetable, general y actual... según se manifiesta en las obras de los más afamados escritores y en el habla de la gente de esmerada educación ${ }^{21}$.

Cuidado y cultivo de la lengua, pues, en beneficio de la conservación de su unidad fundamental. Lo cual obliga a todos los hispanohablantes a sacrificar o, al menos, a relegar, humildemente, lo local o particular en beneficio de lo común o general. Acto de humildad que corresponde no sólo a los americanos, sino también a los españoles, como bien señaló Cuervo: "cuando los españoles conservan fielmente el tipo tradicional, su autoridad es la razón misma; cuando los americanos lo conservamos y los españoles se apartan de él, bien podemos llamarlos al orden y no mudar nuestros usos. Si el beneficio es común, común ha de ser el esfuerzo"22. Porque los españoles, contrariamente a lo que ellos creían durante épocas pasadas muchos siguen creyendo en la actualidad - no son los amos de la lengua, con exclusión de los hispanoamericanos. Cosa que, con humildad encomiable, ha reconocido Dámaso Alonso:

20 Según he tratado de mostrar en el ensayo citado al final de la n. 12.

${ }^{21}$ Cito por la edición de las Obras de Cuervo indicada en la n. 3, pp. 5, 11 y 13 .

22 Cf. el Prólogo de las Apuntaciones citado en la nota anterior, p. 94. (Corresponde a la séptima edición.) 
En el siglo xix era idea general la de que los españoles éramos los amos de nuestra lengua. En el momento del siglo xx en que vivimos, quizá ya esa idea no sea tan general, pero me parece que quedan muchos rastros de ella... Quitar esa idea, o los muchos restos de ella, de la cabeza de los españoles ha sido empeño mío a lo largo de tantos años de mi vida adulta. Hace algunos publiqué un artículo cuyo título era precisamente "Los españoles no somos los amos de nuestra lengua". No lo somos. Los amos de nuestra lengua formamos una inmensa multitud de varios cientos de millones de hombres que hablamos español; todos somos los amos conjuntamente; pero por ser los amos de nuestra lengua todos tenemos deberes ineludibles para con ella, especialmente los millones y millones de hispanohablantes que hemos pasado por una educación culta ${ }^{23}$.

Pero es muy difícil, sin duda, que tanto españoles cuanto hispanoamericanos tengan la modestia de reconocer la sólo relativa validez de sus peculiaridades lingüísticas, y acepten someter lo particular a lo general. Daré algunos ejemplos sintomáticos. En todos — creo- los países hispanoamericanos se ha generalizado el empleo de la familia léxica correspondiente a la moderna computación electrónica. Se trabaja con computadoras o computadores de diversa potencia en los prodigiosos centros de cómputo, de acuerdo con programas computacionales más o menos complejos. Durante los primeros años de aparición de estas máquinas también en España se hablaba de computadores - más que de computadoras -, como en el resto de los países hispánicos. Pero algo después, quizá por rehuir el anglicismo -emancipadora actitud frente a la actual hegemonía estadounidense-, lo sustituyeron por el término ordenador, de indudable procedencia francesa, pasando así del anglicismo avasallador al galicismo hoy decadente. Pero no importa juzgar aquí la pertinencia o acierto de la posición galicista de los españoles, sino el hecho de que tal elección se haya tomado contracorriente e ignorando por completo la opinión —el sentir- de los demás países hispanohablantes. En este caso —al margen de que sea más adecuado o no el término ordenador que el de computadora - , los españoles han dado prueba de que siguen pensando que son ellos los únicos dueños de la lengua

23 Cf. "El español, lengua de centenares de millones de hablantes", en la Memoria del I Congreso Internacional de Lengua Española, editada por Manuel Alvar, Las Palmas de Gran Canaria, 1981, pp. 419-428. (La cita corresponde a las pp. 420-421.) 
española y que pueden disponer de ella a su antojo, sin consideración ninguna de la opinión que puedan tener los otros 18 países hispanohablantes. Y en el diccionario de la Real Academia Española se da, sin más, entrada a la voz ordenador con el moderno significado, como si ella fuera forma legítima y propia de la lengua española, y no una variante aislada. Lo lógico habría sido introducirla - no obstante su virulencia fragmentadora- pero con la apostilla de "españolismo por computadora"24, de igual manera que cualquier voz peculiar de Cuba, México, Chile, o Andalucía, Canarias, etc., si halla cabida en el académico Diccionario, queda señalada con la apostilla de $c u b a-$ nismo, mejicanismo, andalucismo, etc., como si aún siguieran pensando que la lengua española es el dialecto de Castilla. Cosa, hoy, absolutamente inadmisible, ya que

la lengua española reúne en su seno un conjunto de dialectos generales, cada uno de los cuales, a su vez, está integrado por una serie de dialectos particulares - regionales o locales- muy numerosos. Es decir que la lengua abarca tanto el habla de Castilla la Nueva (dialecto castellano nuevo), como el habla de Castilla la Vieja (dialecto castellano viejo), la de Extremadura (dialecto extremeño), la de Andalucía, la de Canarias, la de México (dialecto mexicano), la del Perú, la de Chile, etc., cada una de las cuales abarca varias hablas comarcales o locales (dialecto madrileño, dialecto toledano, dialecto taranconense, etc., dentro del dialecto castellano nuevo), de manera que la lengua es un complejo y variadísimo mosaico de hablas diversas, más o menos diferenciadas entre sí, más o menos agrupables en conjuntos dialectales. Cierto es que algunos de esos dialectos locales pueden disfrutar de un prestigio muy superior al de otros, por razones históricas, políticas, culturales o económicas. Indudablemente que el prestigio del dialecto madrileño — de la norma culta madrileña- es muy superior al prestigio del dialecto taranconense -en lo que éste difiera de aquél- o del dialecto veracruzano, o, inclusive, del dialecto quiteño; indiscutible también que ese habla madrileña culta es una de las más prestigiosas de todas las

${ }^{24}$ En la vigésima edición (1984) de su Diccionario, la Real Academia daba plena entrada a la voz computador, -ra, como designación común y principal de la máquina electrónica en cuestión, mientras que s.v. ordenador remitía, en su cuarta acepción, a "computador electrónico", como entrada básica; pero en la edición de 1991, s.v. ordenador, -ra, ya no hace tal remisión, sino que, también en su cuarta acepción, proporciona la definición de la "máquina electrónica" sin endilgarle, como hubiera debido ser, el calificativo de "españolismo". 
que integran la lengua española. Pero eso no autoriza a identificarla con la lengua española misma ${ }^{25}$.

Otra prueba de que los españoles - no obstante los generosos esfuerzos de Dámaso Alonso- se siguen considerando "los amos de la lengua" es el hecho de que en 1978, cuando se redactó la nueva constitución política española, los diputados constituyentes decidieron cambiar el nombre de la lengua propia de otros 18 países sin acordarse de solicitar la opinión de esas otras naciones, de manera que la lengua española pasó a denominarse oficialmente, en España, lengua castellana, sin que los países hispanoamericanos tuvieran arte ni parte - afortunadamente- en ese desaguisado ${ }^{26}$.

Naturalmente que los hispanoamericanos deberán también supeditar las peculiaridades de sus dialectos a las realizaciones normales del sistema general. Los hablantes del Río de la Plata, por ejemplo, deberán tratar de rectificar, al menos en "situaciones hispánicas", el ensordecimiento rehilado de /ll/ o $\mathrm{de} / \mathrm{y} /$, cada día más frecuente en sus hablas ${ }^{27}$. De igual manera, en el español de México, la falsa concordancia en la secuencia se los, antes comentada, deberá ser combatida en beneficio de la construcción normal se lo con se plural. Y así, siempre que sea necesario, por parte de unos y otros. Todo ello, en beneficio del mantenimiento de la unidad fundamental de la lengua.

Cuya conservación acaso no sea muy difícil, al menos por el momento. Me permiten pensar así diversas circunstancias, entre las cuales no es de escaso significado el hecho de que sean muy pocas las ocasiones en que se haya producido ya una ruptura entre unas y otras normas cultas. En efecto, puede darse el caso de que haya dualidad - $\mathrm{o}$, inclusive, pluralidadde normas igualmente válidas. Como en otro lugar he señala-

25 Más pormenores en mi artículo sobre "El supuesto arcaísmo del español americano", ALM, 7 (1968-69), 85-110. (La cita corresponde a las pp. 97-99.)

${ }^{26}$ Me permito remitir al lector a mi ensayo "¿Lengua española o castellana?: Un problema de política lingüística”, en Serta Philologica F. Lázaro Carreter, Cátedra, Madrid, 1983, t. 1, pp. 309-314. (Recogido también en mi libro de Estudios de lingüistica española, UNAM, México, 1986, pp. 7-15.)

27 Recuerdo la sorpresa — debida a incomprensión- que causó entre un grupo de hispanohablantes de diversa procedencia una frase dicha por un lingüista uruguayo en que se acumularon tres palatales rehiladas: [só sébo la sábe]. 
do 28 , la validez de dos formas lingüísticas divergentes puede deberse - entre otras cosas - al hecho de que cada una de ellas cuente con respaldo de un elevado número de hablas de prestigio, o al alto prestigio de alguna de ellas en particular. No son aún muchos los casos en que la lengua española ofrezca dos posibilidades de realización distintas, pero de validez equivalente. Pero sí existen. Uno de ellos es el que se refiere a la oposición fonológica entre dentoalveolar sibilante /s/ e interdental ciceante $/ \theta /$, oposición neutralizada en casi todas las hablas hispánicas - con resultado seseante en la gran mayoría de ellas, o ciceante en algunas otras-, pero mantenida en castellano y en otras hablas peninsulares. Dado el alto prestigio histórico-cultural del dialecto castellano, la distinción s/ $\theta$ debe considerarse normal dentro de la lengua española, así como es normal dentro de este mismo sistema lingüístico la solución, absolutamente mayoritaria, que es el seseo.

Cosa semejante sucede en el caso del yeísmo, fenómeno propio de la mayor parte de las hablas hispánicas, entre las cuales figura un buen número de dialectos castellanos, incluido el madrileño. Pero la distinción entre la palatal lateral $/ \lambda /$ y la central /y/ tiene una firme raíz histórica que, unida al hecho de que se haya mantenido en algunas hablas españolas y americanas, justifica su conservación como norma propia de la lengua, a la par que el más generalizado yeísmo.

De igual modo, en el caso de los pronombres personales átonos de tercera persona, la distribución funcional de origen latino - lo para complemento directo y le para indirecto-, que es la norma general en Hispanoamérica, no invalida el fenómeno esencialmente castellano del leísmo, por cuanto que fue práctica común de muchos de los grandes escritores del Siglo de Oro - las autoridades clásicas del idioma- y de siglos sucesivos. De manera que habremos de admitir que, también en este caso, existe dualidad en la norma hispánica: leísmo en la castellana frente a distinción etimológica en las demás.

Existe asimismo pluralidad de normas en el caso de la distinción funcional entre las dos formas del pretérito de indicativo, canté frente a he cantado, cuya distribución funcional es distinta en la norma culta castellana respecto de la mexicana y

28 Cf. "El español de América y la norma lingüística hispánica”, en El español de América, cit. supra n. 16. (Recogido también en mi libro Nuevos estudios de lingüística hispánica, pp. 127-136, por donde cito.) 
- sospecho- de otras normas cultas americanas. En la primera de ellas, las diferencias existentes entre los dos pretéritos son de carácter fundamentalmente temporal, en tanto que en la norma mexicana se trata de diferencias básicamente aspectuales, de valor imperfectivo en el caso de la forma compuesta he cantado, pero perfectivo en el caso de la forma simple canté 29 .

En lo que respecta a los tratamientos apelativos de segunda persona del singular, habría que admitir que existe también duplicidad de normas, por cuanto que el voseo - aun habiendo quedado relegado, históricamente, a un sector rural de los hispanohablantes - ha sido dignificado en siglos posteriores merced a su empleo por parte de hablantes cultos de amplias regiones hispánicas, desde la Argentina hasta el sur de México.

Duplicidad de normas hay también en el caso de las formas pronominales de la segunda persona plural: vosotros en España, ustedes, en América. Lo cual acarrea también diversidad en el caso de los posesivos correspondientes: vuestro en la norma española, suyo en la americana.

Basten estos ejemplos - no creo que pudieran darse muchos más- para probar que el número de casos de fractura ${ }^{30}$ en la norma hispánica general es todavía, felizmente, muy bajo ${ }^{31}$.

Una segunda consideración que me permite ver el futuro inmediato de la lengua española con optimismo es el hecho de que las anomalías, las desviaciones respecto de esa norma hispánica ideal, que pueden observarse en cada una de las normas cultas particulares, son muy reducidas en número. En el caso de la norma lingüística mexicana, creo que no suman siquiera una decena los casos de verdadera anomalía: en el terreno fonético, sólo uno; en el morfosintáctico, poco más de media docena. El primero de ellos se refiere a la diptongación de hiatos: eó > jó (peor > pjor) y oé > wé (poeta > pweta), fenó-

${ }^{29}$ Cf. mi artículo "Sobre el uso del pretérito en el español de México", en $H D A$, t. 2, pp. 373-386.

${ }^{30}$ La duplicidad de normas igualmente válidas es, obviamente, indicio de fragmentación lingüística.

${ }^{31}$ Algunos más pueden hallarse, actualmente, en proceso de gestación. Tal cosa sucede, por ejemplo, en el uso de la preposición hasta en la norma lingüística mexicana, donde puede expresar el límite final de una acción durativa, de acuerdo con la norma hispánica general ("Trabaja hasta las doce"), pero donde puede también emplearse para señalar el límite inicial de un acto ("Se casó hasta los 40 años"). Cf., a este respecto, mi estudio "Precisiones sobre el uso mexicano de la preposición hasta", ALHis, 6 (1990), 293-321. 
meno ampliamente aceptado - aunque no generalizadodentro del habla culta mexicana ${ }^{32}$. En el dominio de la morfosintaxis, la falsa pluralidad del pronombre personal objetivo, antes comentado, en la secuencia se los. En segundo término, la concordancia del verbo impersonal haber con su complemento directo - también antes señalada- en construcciones del tipo "Hubieron fiestas" o "Aquí habemos muchos". En tercer lugar, la adjetivación del adverbio medio, fenómeno menos generalizado que los anteriores, pero ya incrustado en el habla culta: "Son medios tontos" o "Están medias locas". Suele también establecerse concordancia indebida entre el indefinido poco y su término: "una poca de agua" o "necesita una poquita de vergüenza". En quinto lugar, el antes señalado empleo de la preposición hasta como indicadora del límite inicial de acción o del momento puntual en que ésta se ejecuta: "Lo entierran hasta pasado mañana”. Son también cada día más frecuentes los casos de (de) queismo ${ }^{33}$ de los tipos "Resulta de que no lo sabía" y "Estoy seguro (-) que lo hará", fenómeno cada día más frecuente en todos los países de lengua española, al grado de que acaso pudiera ya hablarse de duplicidad en la norma ${ }^{34}$. En séptimo término, el empleo del presente de indicativo regido por aún o todavía no en construcciones en que la norma hispánica pide el uso del pretérito compuesto o antepresente: "Todavía no abren las puertas" 35 . Acaso olvide alguna que otra, pero no serán muchas ${ }^{36}$.

32 Cf. Giorgio Perissinotto, Fonología del español hablado en la ciudad de México. Ensayo de un método sociolingüistico, El Colegio de México, México, 1975.

33 Estudiado puntualmente por MARINA ArJona en su artículo sobre las “Anomalías en el uso de la preposición de en el español de México", ALM, 16 (1978), 67-90.

34 Recuerdo los estudios de Ambrosio Rabanales sobre "Queísmo y dequeísmo en el español de Chile", en Estudios filológicos y lingüisticos. Homenaje a Ángel Rosenblat, Instituto Pedagógico, Caracas, 1974, pp. 413-444, y el de Paola Bentivoglio, "Queísmo y dequeísmo en el habla culta de Caracas", en la memoria del 1975 Colloquium on Hispanic Linguistic, eds. M. Aid et al., Georgetown University Press, Washington, DC, 1976, pp. 19-25.

35 Sobre todas estas desviaciones lingüísticas mexicanas y algunas otras de menor trascendencia he escrito en la ponencia dedicada a las "Anomalías en la norma lingüística mexicana", Actas del X Congreso de la Asociación Internacional de Hispanistas, Universidad, Barcelona, 1992, t. 4, pp. 1221-1226. (Recogida también en mi libro de Ensayos sobre el español de América, UNAM, México, 1993, pp. 148-156.)

36 No tomo en consideración las más abundantes diferencias léxicas, que en la mayoría de los casos no son propiamente desviaciones de una 
Una tercera circunstancia que justifica mi moderado optimismo es el hecho de que no existe la fractura que suele suponerse entre español de América y español de España. En efecto, las modalidades europeas de nuestra lengua no presentan una fisonomía general común a todas ellas que las distingan, en cambio, de las hablas hispanoamericanas. Las cuales, por su parte, están también muy lejos de presentar una fisonomía común que las hermane y defina. Revisemos, siquiera sea superficialmente, los rasgos que suelen invocarse como distintivos de las hablas situadas a uno y otro lado del Atlántico. El seseo americano frente a la distinción española entre /s/ y $/ \theta /$ — que sería el caso más claro y contundente- no creo que tenga la contundencia imaginada, puesto que seseo hay en gran parte de las hablas españolas, en especial andaluzas y canarias. El yeísmo, frente a la oposición $l l / y$, no separa de ninguna manera al español americano del europeo, por cuanto que yeísmo hay en casi toda España y, en cambio, la conservación de la palatal lateral $/ \lambda /$ se da no sólo en Castilla la Vieja, sino también en amplias zonas de América y en todo un país, el Paraguay, como realización normal. El rehilamiento del fonema palatal central $(y>z ̌)$ no es exclusivo, ni mucho menos, del Río de la Plata, sino que se puede recoger en hablas de todo el amplio mundo lingüístico hispánico, aunque sin que alcance en ellas la universalidad que ha alcanzado en las hablas rioplatenses. La aspiración y aun pérdida de $-s$ implosiva, tan frecuente en muchas hablas americanas — no sólo antillanas y caribeñas- es también común en hablas españolas - y no sólo en las andaluzas y canarias.

Dentro del aún más revelador dominio de la morfología y de la sintaxis, los estudios hechos hasta ahora muestran que no existen fenómenos que permitan agrupar de una parte a las hablas americanas y de otra a las españolas. El empleo del pronombre ustedes como forma de segunda persona plural, en

norma establecida e indiscutible, sino creaciones diversas, independientes y originales en cada habla particular. Tan válida es en lengua española la voz milpa como maizal, o maguey como pita, puesto que todas ellas son las palabras usuales en hablas de alto prestigio y están, histórica y etimológicamente, bien justificadas. Pero acaso podrían tenerse por anomalías o desviaciones de la norma hispánica usos léxicos dialectales, como podría ser el mexicanismo banqueta por 'acera' o el españolismo fallo por 'falla'. Mas no son las diferencias léxicas las que ponen en verdadero peligro el futuro del idioma. 
lugar de vosotros, no es exclusivo de América, pues tiene también vigencia en Andalucía y Canarias. La distinta distribución mexicana, respecto de la castellana, de las dos formas de pretérito canté y he cantado no es desconocida en hablas del norte y noroeste peninsular, además de que, por otro lado, tampoco coincide con la distribución propia de otros dialectos hispanoamericanos. El leísmo castellano no sólo difiere de las distinguidoras hablas americanas, sino también de las andaluzas y canarias. La mayor parte de las peculiaridades morfosintácticas que se encuentran en algunas hablas americanas - como el peculiar uso mexicano de la preposición hasta o la singular perífrasis ecuatoriana formada por el verbo dar seguido de gerundio con sentido exhortativo ${ }^{37}$ - se oponen a los usos castellanos exactamente igual que a los de las demás hablas hispanoamericanas.

Tampoco existe divorcio alguno en el uso de las unidades sintácticas mayores a uno y otro lado del Atlántico. La estructura oracional de la cláusula culta es, en promedio, casi exactamente igual en Madrid que en las ciudades hispanoamericanas, y la distribución de oraciones coordinadas y subordinadas es la misma en todas ellas. Nada hay que permita decir que la estructura sintáctica del habla castellana sea diferente de la propia de las hablas hispanoamericanas ${ }^{38}$. Coincidencia absoluta que encontró asimismo Sung Jae Lee Kim en el empleo de los pronombres relativos en los dialectos castellano e hispanoamericanos $^{39}$ : la frecuencia de su empleo y sus peculiaridades funcionales son las mismas en todas partes. $\mathrm{Y}$ yo he podido constatar que inclusive las anomalías o desviaciones respecto de los usos canónicos de los relativos son también las mismas en España y América, de manera que el fenómeno de la "despronominalización" de los relativos se da por igual en una y otra parte: "Tiene una casa que la cuida mucho" es construcción que puede oírse por doquier, según he advertido en otros

37 Cf. Humberto Toscano Mateus, El español en el Ecuador, C.S.I.C., Madrid, 1953, p. 284.

38 Cf. mi artículo sobre "La estructura del discurso en el habla de Madrid”, ALHis, 1 (1985), 129-142. (Recogido también en mi libro Análisis gramatical del discurso, 2a ed., UNAM, México, 1987, pp. 151-163.)

${ }^{39} \mathrm{Cf}$. su tesis doctoral sobre la Sintaxis de los relativos en el habla culta de seis ciudades hispánicas: Bogotá, Buenos Aires, Caracas, México, Madrid y Santiago de Chile, UNAM, México, 1991. 
ensayos $^{40}$. Y lo mismo en el caso del desdoblamiento de cuyo en que su: "Iba con una muchacha de Córdoba que su hermano es médico". Y claro está que las divergencias debidas a peculiaridades particulares de unas y otras hablas hispánicas distinguen a cada una de ellas de todas las demás, y no sólo de la castellana. La cual está inserta - como una más, como una entre las otrasen un conjunto de hablas hispánicas muy afines, como lo están también cada una de las hablas americanas dentro del total de la lengua española. El castellano es uno de tantos dialectos hispánicos, como el chileno o el colombiano, el argentino o el mexicano, el puertorriqueño o el paraguayo, e inclusive el andaluz o el canario. En algunos casos, el castellano coincide con el mexicano y discrepa del andaluz —en la conservación de - $s$ implosiva, por ejemplo, frente a su aspiración o pérdida-, de igual manera que el mexicano de la capital coincide a veces con el madrileño y difiere del veracruzano o del yucateco.

No creo que exista, por consiguiente, una clara bipartición de nuestra lengua en dos grandes modalidades, española y americana. La variedad, la diferenciación, es mucho más amplia y complicada ${ }^{41}$, aunque no sea grave o peligrosa todavía.

Pero el riesgo, el peligro, existe sin duda alguna. Si no de fragmentación total, sí de diversificación relativa, que pueda dificultar la cabal comprensión entre los pueblos hispanoamericanos. De ahí que no debamos descuidarnos frívolamente, sino esforzarnos en cambio por mantener nuestra lengua lo más homogénea, lo más uniforme y comprensible en todas partes, conservándola "en un tenor", como se propuso hacer Nebrija, y no sólo a través de los siglos, según el gran humanista andaluz deseaba, sino a todo lo ancho y largo de los extensos territorios de lengua española.

JuAN M. LOPE BLANCH

El Colegio de México

Universidad Nacional Autónoma de México

40 Cf. "Despronominalización de los relativos", HL, 1 (1984), 257-272, y "Duplicaciones pronominales en el habla culta de Madrid", en el Homenaje a Bernard Pottier, Klincksieck, Paris, 1988, t. 2, pp. 493-498.

41 Según he tratado de mostrar en otra ocasión: cf. mi ponencia sobre “La norma lingüística en España y América”, presentada en el X Seminario de Investigación y Enseñanza de la Lingüística, Valparaíso, 6-8 octubre 1993, en cuyas Actas se publicará próximamente. 